\title{
Different Ecological Affinities and Aggressiveness Patterns Among Didymella rabiei Isolates from Sympatric Domesticated Chickpea and Wild Cicer judaicum
}

\author{
O. Frenkel, A. Sherman, S. Abbo, and D. Shtienberg
}

First and third author: The Levi Eshkol School of Agriculture, The Hebrew University of Jerusalem, Rehovot 76100, Israel; second author: Genomics Department, The Volcani Center, Agricultural Research Organization, Bet Dagan 50250, Israel; and fourth author: Department of Plant Pathology and Weed Research, The Volcani Center, Agricultural Research Organization, Bet-Dagan 50250, Israel. Accepted for publication 11 December 2007.

\begin{abstract}
Frenkel, O., Sherman, A., Abbo, S., and Shtienberg, D. 2008. Different ecological affinities and aggressiveness patterns among Didymella rabiei isolates from sympatric domesticated chickpea and wild Cicer judaicum. Phytopathology 98:600-608.

Domesticated chickpea (Cicer arietinum) and its wild relative $C$. judaicum grow in sympatric distribution in Israel and both are susceptible to Ascochyta blight caused by Didymella rabiei. C. arietinum was grown for millennia in drier and hotter Levantine spring conditions while $C$. judaicum grows in the wetter and milder winters. Accordingly, it is possible that D. rabiei isolates originated from $C$. arietinum are adjusted to the less

$(P<0.001)$ while no such differences were detected between isolates from $C$. judaicum. D. rabiei isolates from wild and domesticated origins were used to inoculate nine $C$. judaicum accessions and two domesticated chickpea cultivars and their aggressiveness patterns were determined using five measures. On domesticated chickpea, isolates from domesticated origin were significantly more aggressive in four out of the five aggressiveness measures than isolates from wild origin. On C. judaicum, isolates from wild origin were generally more aggressive than isolates from domesticated origin. The results suggest that the habitat segregation between wild and domesticated Cicer influences the pathogens ecological affinities and their aggressiveness patterns.
\end{abstract} favorable spring conditions. Here, 60 isolates from both origins were tested in vitro for their hyphal growth at 15 and $25^{\circ} \mathrm{C}$. Isolates from C. arietinum had a significantly larger colony area at $25^{\circ} \mathrm{C}$ than at $15^{\circ} \mathrm{C}$
Additional keywords: comparative epidemiology, ecological requirements, incubation period, sympatric pathosystems, wild hosts.
Selection pressures imposed by plant pathogens are a major evolutionary force operating in domesticated as well as in wild plant communities (7). However, contrary to the situation in domesticated fields, diseases in wild ecosystems usually do not devastate their hosts and in most cases do not take the form of severe epidemics (10). Since the primary and secondary centers of origin for domesticated crops are often the place of origin for their pathogens (20), it is likely that the destructive crop pathogens affecting domesticated crops evolved from their wild sympatric species and have become aggressive in the course of coevolutionary processes under domestication (15). Clarifying the evolutionary relationships between wild and domesticated hosts on the one hand, and their respective pathogens on the other hand, can be done by challenging both host groups with pathogen isolates originating from wild and domesticated systems. Indeed, such work was done with a number of Near Eastern cereals $(10,11,21)$, but information about wild legumes and their pathogens is scarce.

Throughout West Asia, a sympatric system including wild legumes and their domesticated derivatives prevails since the dawn of Near Eastern farming systems (22). In the case of chickpea, these include the cultigen (Cicer arietinum) and a number of annual and perennial Cicer species in eastern Turkey (the wild progenitor $C$. reticulatum, C. pinnatifidum, and C. bijugum among others) (19,35). In the southern Levant, domesticated chickpea is grown sympatrically with $C$. judaicum. This taxon

Corresponding author: D. Shtienberg; E-mail address: danish@ volcani.agri.gov.il

doi:10.1094/PHYTO-98-5-0600

(C) 2008 The American Phytopathological Society grows in patchy distribution in stony/rocky habitats in Israel and neighboring territories in sites with annual precipitation $>490 \mathrm{~mm}$ and altitude $<800 \mathrm{~m}(6)$.

Ascochyta blight caused by Didymella rabiei (Kovachevski) von Arx [anamorph: Ascochyta rabiei (Passerini) Labrousse] affects both domesticated chickpea $(4,26)$ and its wild relative C. judaicum (12). Late winter conditions in the Mediterranean Basin, namely, frequent rains, winds, and mild temperatures may result in total destruction of the domesticated crops by Ascochyta blight (29). In the domesticated crop the disease may affect all aerial parts of the plants. On leaflets, the fungal lesions are round or elongated, bearing irregularly depressed brown dots. On the green pods, the lesions are usually circular with dark margins and have pycnidia arranged in concentric circles. On stems and petioles, the lesions are brown and elongated ( 3 to $4 \mathrm{~cm}$ long), bearing black dots and often girdle the affected portion. When lesions girdle the stem, the portion above the point of attack rapidly dies. If the main stem is girdled at the collar region, the whole plant dies (26). In $C$. judaicum the pathogen causes grey lesions and girdling of the stem and branches, which occasionally lead to the collapse of the upper plant parts but only rarely cause death of whole plants (12).

The recent isolation of $D$. rabiei from wild annual $C$. judaicum by Frenkel et al. (12) enabled to study the sympatric pathosystem of chickpea and its wild relatives. D. rabiei isolates, originated from $C$. judaicum, were virulent toward a number of Cicer species including the wild progenitor of chickpea $C$. reticulatum and two wild Turkish species, $C$. pinnatifidum and $C$. bijugum. In domesticated chickpea ( $C$. arietinum), isolates from $C$. judaicum induced relatively high disease severity. It was also demonstrated that $D$. rabiei isolates originated from domesticated chickpea and 
C. judaicum may infect $C$. judaicum accessions (12). Although wild Cicer spp. and chickpea are sympatric throughout West Asia, their growth cycle is different (3). In traditional farming across the region chickpea is a spring sown crop, a practice that reduces the risk of severe Ascochyta blight epidemics by avoiding growth during the rainy season (2,3). Millennia of spring cropping in sympatry with native wild population (that assume growth following the autumn rains) actually provide two distinct niches in terms of the temperature and moisture regimes; the wild host which grows mainly during the cool rainy winters, and the domesticated host which develops during the warmer and drier spring months (12). Under such conditions it is possible that the respective pathogen populations will adjust their ecological requirements to the prevailing conditions. Such adaptation was reported, for example by Harikrishnan and Yang (14) for Rhizoctonia solani.

Several important questions arise from the above. (i) Do isolates from wild origin differ from those from domesticated origin in their temperature requirements? (ii) Does the fact that epidemics in the wild are scarce imply that isolates from wild $C$. judaicum are generally less aggressive than isolates originated from domesticated chickpea? (iii) Can we detect distinct aggressiveness patterns among $D$. rabiei isolates from wild versus domesticated origin? This study was carried out to answer the above questions by testing the aggressiveness of $D$. rabiei isolates originated from both $C$. judaicum and domesticated chickpea on a range of wild $C$. judaicum accessions and on two domesticated chickpea cultivars differing in their response to the pathogen. Aggressiveness was defined herein as the quantity of disease induced by a pathogenic isolate to a susceptible host (12). The results are discussed in light of the ecological differences between Levantine chickpea cropping systems and natural ecosystems harboring wild Cicer.

\section{MATERIALS AND METHODS}

Collection and maintenance of fungal material. Thirty-one D. rabiei isolates originated from $C$. judaicum and 29 isolates originated from domesticated chickpea were collected from different locations around central and northern Israel in the springs (March to May) of 2004 to 2006. The pathogens were isolated from living plants tissues and maintained as single spore colonies in petri dishes containing potato dextrose agar (PDA, Difco, France). All 60 isolates were identified as D. rabiei using morphological characterization based on mycelium and conidial shape, color, and size among other characters as described previously (12).

Effect of temperature on colony hyphal growth in vitro. The hyphal growth of the 60 isolates was determined in vitro at 15 and $25^{\circ} \mathrm{C}$ which represent the average daily temperatures in central Israel in February to March and April to May, respectively. Agar pieces ( $8 \mathrm{~mm}$ in diameter) were cut with cork borer from the edge of 14-day-old colonies, placed in the center of petri dishes containing PDA, sealed with parafilm, and put in growth chambers at 15 and $25^{\circ} \mathrm{C}$. The diameter of each colony was measured after 9 days in two perpendiculars directions and the area (in $\mathrm{cm}^{2}$ ) was calculated. The experiment was laid out in a completely randomized design. Each treatment (isolate) was repeated four times (petri dishes) and the experiment was conducted twice. When analyzed together, the experiments effects were insignificant $(P=$ $0.28)$.

Statistical analyses of the data were performed with the JMP 5.0 software for windows (SAS Institute, Cary, NC). To enable analysis of variance (ANOVA) and multiple means comparisons, observed data were approximately normalized by the third root of the colony area $(3 \sqrt{ }$ transformation). Multiple comparisons of the means were done with the Tukey Kramer honestly significant difference (HSD) test $(\alpha=0.05)$.
Collection and maintenance of plant material. Two domesticated chickpea cultivars and nine $C$. judaicum accessions were used in this study. Cultivar Spanish White is highly susceptible to $D$. rabiei and cv. Yarden is moderately resistant to $D$. rabiei. Seeds were planted in 0.5-liter pots and the plants were maintained in greenhouse at 15 to $23^{\circ} \mathrm{C}$, under natural light, for 21 days. The nine accessions of $C$. judaicum were chosen from the working collection of Ben David et al. (6), spanning the known distribution of this species in Israel (Table 1). C. judaicum seeds were scarified to enhance germination and seedlings were planted in 0.5-liter pots and grown for 28 days under the same conditions as the chickpea cultivars.

Aggressiveness of $D$. rabiei isolates from $C$. judaicum and $C$. arietinum. Five isolates were chosen from the collection and tested for their aggressiveness pattern. Of these, two were collected in mid-April from diseased plants in commercial chickpea fields: Isolate N04 was collected in 2004 from Bet Natif $\left(31^{\circ} 41^{\prime} \mathrm{N}\right.$ $\left.34^{\circ} 59^{\prime} \mathrm{E}\right)$ and isolate B05 was collected in 2005 from Bakoa' $\left(31^{\circ} 49^{\prime} \mathrm{N} 34^{\circ} 55^{\prime} \mathrm{E}\right)$. The other three were isolated from diseased C. judaicum stems in the second week of March: isolate M305 and isolate Y105 were collected in 2005 from Gale'd $\left(32^{\circ} 33^{\prime} \mathrm{N}\right.$ $\left.35^{\circ} 03^{\prime} \mathrm{E}\right)$ and Ramot Menashe forest $\left(32^{\circ} 34^{\prime} \mathrm{N} 35^{\circ} 04^{\prime} \mathrm{E}\right)$, respectively. Isolate S306 was collected in 2006 from Haela Valley $\left(31^{\circ} 41^{\prime} \mathrm{N} 35^{\circ} 00^{\prime} \mathrm{E}\right)$. Colony area of the chosen isolates from each origin did not differ from the average colony area of their origin (i.e., C. judaicum or C. arietinum) in more than the standard deviation, in both temperatures. Representative isolates from each origin were chosen, rather than randomly sampled, from the collection to avoid testing extreme phenotypes. To corroborate the morphological identification, partial sequencing of the ribosomal internal transcribed spacer (ITS) was performed by polymerase chain reaction (PCR) amplification, using the primer pairs ITS1 and ITS4. The comparison between sequences of D. rabiei isolates originated from $C$. judaicum and domesticated chickpea revealed $100 \%$ similarity as described by Frenkel et al. (12). All isolates were also positively characterized as D. rabiei using 10 specific sequence tagged microsatellite (STMS) markers developed for D. rabiei by Geistlinger et al. (13) and specific primers for the mating type locus developed by Barve et al. (5). The isolates were maintained as single spore colonies in petri dishes with PDA incubated in a growth chamber at $19 \pm 1{ }^{\circ} \mathrm{C}$ under alternating cycle of $12 \mathrm{~h}$ of near UV light and $12 \mathrm{~h}$ of darkness, and renewed every 30 days. Fourteen days before inoculation experiments, the isolates were transferred to chickpea seed meal agar (CSMA) medium containing $50 \mathrm{~g}$ of chickpea flour, $20 \mathrm{~g}$ of dextrose, and $20 \mathrm{~g}$ of agar per liter of distilled water (16) to enhance sporulation.

Aggressiveness of fungal isolates originated from domesticated chickpea and C. judaicum was determined on both hosts. Plants were sprayed with conidial suspension of the pathogen $\left(3 \times 10^{5}\right.$ spores/ml) with an air pressure hand-sprayer to run-off. Then, the plants were covered with two clear polyethylene bags and placed in the growth chamber at $19 \pm 1^{\circ} \mathrm{C}$. This temperature is about the

TABLE 1. Locations of the nine Cicer judaicum accessions, spanning the known distribution of the species in Israel $^{\mathrm{z}}$

\begin{tabular}{llcc}
\hline $\begin{array}{l}\text { Accession } \\
\text { number }\end{array}$ & Site & Latitude & Longitude \\
\hline Cj1 & Kesalon & $31^{\circ} 46^{\prime} \mathrm{N}$ & $35^{\circ} 01^{\prime} \mathrm{E}$ \\
Cj19 & Menora & $31^{\circ} 55^{\prime} \mathrm{N}$ & $35^{\circ} 02^{\prime} \mathrm{E}$ \\
Cj24 & E'ziona & $31^{\circ} 41^{\prime} \mathrm{N}$ & $35^{\circ} 00^{\prime} \mathrm{E}$ \\
Cj36 & Bakoa' & $31^{\circ} 49^{\prime} \mathrm{N}$ & $34^{\circ} 56^{\prime} \mathrm{E}$ \\
Cj64 & Modii'n & $31^{\circ} 54^{\prime} \mathrm{N}$ & $34^{\circ} 59^{\prime} \mathrm{E}$ \\
Cj99 & Regavim & $32^{\circ} 31^{\prime} \mathrm{N}$ & $35^{\circ} 01^{\prime} \mathrm{E}$ \\
Cj105 & Sollelim & $32^{\circ} 44^{\prime} \mathrm{N}$ & $35^{\circ} 13^{\prime} \mathrm{E}$ \\
Cj112 & Ibtin & $32^{\circ} 22^{\prime} \mathrm{N}$ & $35^{\circ} 02^{\prime} \mathrm{E}$ \\
Cj120 & Mata' & $31^{\circ} 42^{\prime} \mathrm{N}$ & $35^{\circ} 03^{\prime} \mathrm{E}$ \\
\hline
\end{tabular}

z Details provided by Ben-David et al. (6). 
average of the temperatures used in the hyphal growth experiments. Water-sprayed plants of each species were used as control. The bags were removed $24 \mathrm{~h}$ later and the plants were left in the same growth chamber for the duration of the experiment. The plants were visually inspected for the appearance of symptoms 4 , $5,6,7,8,11,13,15$, and 20 days after inoculation. The appearance of first disease symptoms was recorded and disease severity (the proportion of affected plant area, in percent) was determined visually. Each treatment (D. rabiei isolate $\times$ chickpea cultivar or $C$. judaicum accession) was repeated four times. The experiment was laid out in completely randomized design and was conducted twice. Five different aggressiveness measures representing stages of the infection process and disease development were used as follow. (i) The incubation period was determined as the time (in days) between inoculation and the appearance of first disease symptoms; (ii) Rate of disease development: Disease severity records (in percent) were transformed to logit values (logit $=$ $\ln [\mathrm{Y} /(100-\mathrm{Y})])$ where $\mathrm{Y}$ represents disease severity values (between 0.1 and $99.9 \%$ ). The slope of the linear-transformed disease progress curves is an estimate for the apparent infection rate $(r)$; (iii) The time (in days) that passed between incubation and $10 \%$ disease severity $\left(\mathrm{T}_{10}\right)$, was estimated from the logit transformed disease progress curves; (iv) Final disease severity (in percent) 20 days after inoculation; and (v) The area under the disease progress curve (AUDPC in $\% \times$ days) was calculated using all disease assessment records and represents the intensity of the entire epidemic.

To enable ANOVA and multiple means comparisons, disease severity values were approximately normalized by the arcsine square-root transformation prior to analysis. Since only two isolates from domesticated origin and three isolates from wild origin were used, we are unable to draw conclusions concerning hostpathogen specialization in its broad sense. A host species-isolate origin interaction term is biologically meaningless with such small numbers of tested isolates even if proven to be statistically significant. Therefore, being unable to treat this question with the present data we analyzed the results from the chickpea cultivars and the C. judaicum accessions separately. The following general linear ANOVA model was used $\mathrm{Y}_{\mathrm{ikj}}=\mu+\mathrm{M}_{\mathrm{i}}+\mathrm{C}_{\mathrm{k}}+\mathrm{F}_{\mathrm{j}}\left(\mathrm{C}_{\mathrm{k}}\right)+\mathrm{M}_{\mathrm{i}} \times$ $\mathrm{C}_{\mathrm{k}}+\mathrm{M}_{\mathrm{i}} \times \mathrm{F}_{\mathrm{j}}\left(\mathrm{C}_{\mathrm{k}}\right)$ when $\mathrm{Y}_{\mathrm{ikj}}$ represents the excepted disease measure variable; $\mu$ represents the true mean; $M_{i}$ is the cultivar or C. judaicum accession effect; $\mathrm{C}_{\mathrm{k}}$ is the isolate origin effect (C. judaicum or domesticated chickpea); $\mathrm{F}_{\mathrm{j}}\left(\mathrm{C}_{\mathrm{k}}\right)$ stands for the isolate effect nested within each isolate origin (analyzed as a random effect); $M_{i} \times C_{k}$ is the interaction between cultivar or accession and isolate origin; and $\mathrm{M}_{\mathrm{i}} \times \mathrm{F}_{\mathrm{j}}\left(\mathrm{C}_{\mathrm{k}}\right)$ is the interaction between cultivar or $C$. judaicum accession and each isolate nested within isolate origin (analyzed as a random effect). Multiple comparisons of the means were done with the Tukey-Kramer (HSD) test $(\alpha=0.05)$. Data from each experiment were analyzed independently. Conclusions derived from the two experiments were similar; therefore, results of one experiment are present herein.

\section{RESULTS}

Effect of temperature on colony hyphal growth. The linear ANOVA models used to compare the hyphal growth phenotype at the different temperatures were highly significant and explained $84 \%$ of the observed variation. All of the main factors (temperature and isolate origin) and their interactions (temperature $\times$ isolate origin; isolate nested within isolate origin and temperature $\times$ isolate nested within isolate origin) were highly significant $(P<$ 0.001). Different growth phenotypes were detected between isolates from the different origins. Isolates originated from domesticated chickpea had the largest average colony area at $25^{\circ} \mathrm{C}$ (mean $=2.76 \mathrm{~cm}^{2}$ and standard deviation $\left.(\mathrm{SD})=1.02\right)$. The frequency distribution of the isolates departed from normality according to Shapiro-Wilk test $(W<0.001)$ and had a positive skewness with colonies area ranging between 1.80 and $5.50 \mathrm{~cm}^{2}$ (Fig. 1A). The same isolates had a significantly smaller $(P<$
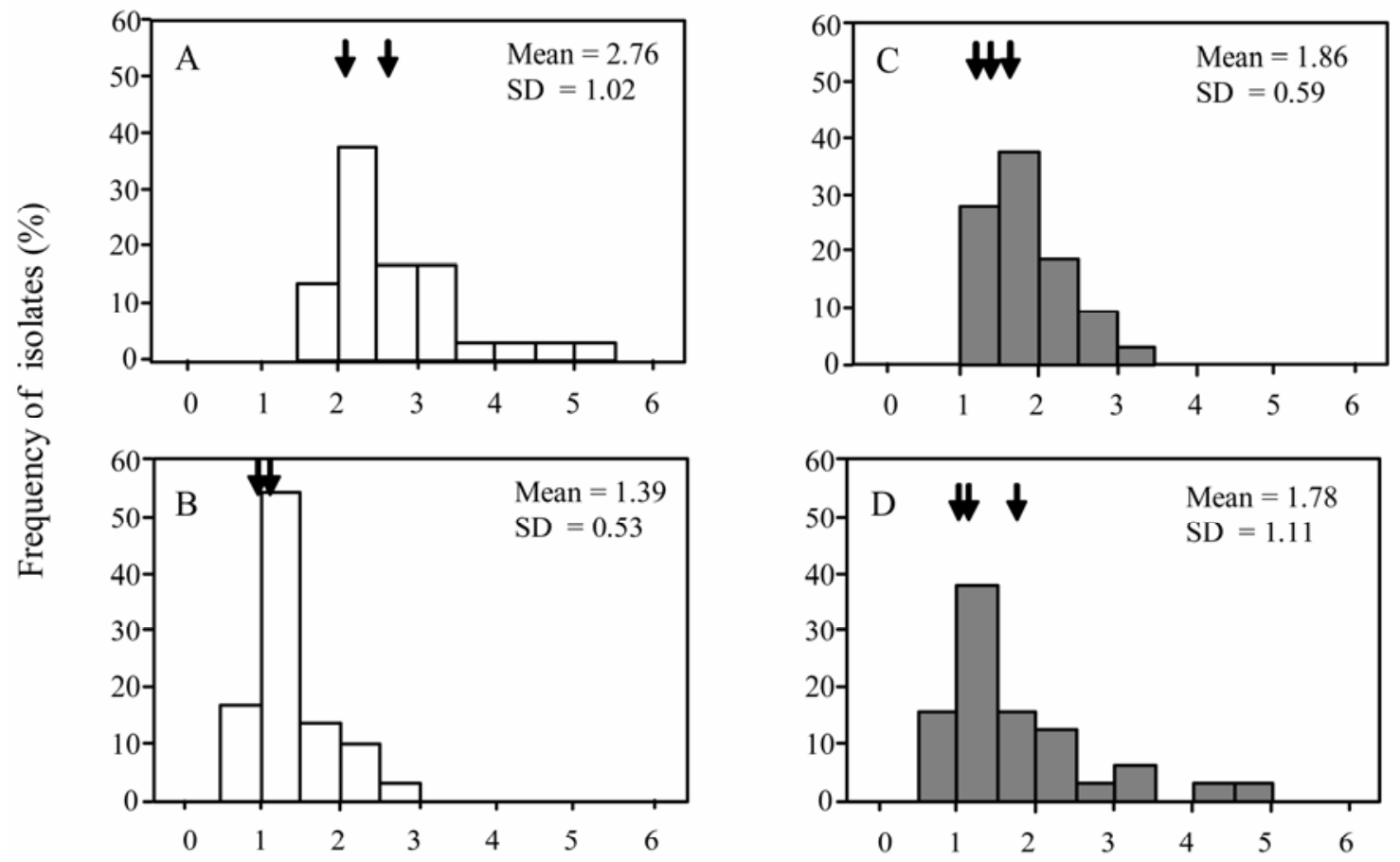

Colony area $\left(\mathrm{cm}^{2}\right)$

Fig. 1. Frequency distribution of hyphal growth area of isolates originated from Cicer judaicum and C. arietinum at 15 and $25^{\circ} \mathrm{C}$. Distribution of 29 isolates originated from $C$. arietinum at $\mathbf{A}, 25^{\circ} \mathrm{C}$ and $\mathbf{B}, 15^{\circ} \mathrm{C}$. Distribution of 31 isolates originated from $C$. judaicum at $\mathbf{C}, 25^{\circ} \mathrm{C}$ and $\mathbf{D}, 15^{\circ} \mathrm{C}$. Arrows indicate the mean colony area of the isolates that were used in the aggressiveness experiments. Average colony area $\left(\mathrm{in}^{2}\right.$ ) and standard deviation of the mean for each distribution are indicated in the graphs. 
$0.001)$ average colony area when incubated at $15^{\circ} \mathrm{C}(1.39 \pm$ $0.53 \mathrm{~cm}^{2}$ ). The frequency distribution at $15^{\circ} \mathrm{C}$ also departed from normality $(W<0.001)$ and had positive skewness but the range of colony area was smaller, between 0.75 and $2.76 \mathrm{~cm}^{2}$ (Fig. 1B).

The average colony area of isolates originated from $C$. judaicum incubated at $15^{\circ} \mathrm{C}$ did not differ significantly from those incubated at $25^{\circ} \mathrm{C}\left(1.78 \pm 1.11\right.$ and $1.86 \pm 0.59 \mathrm{~cm}^{2}$, respectively). Distribution of isolates originated from $C$. judaicum incubated at $25^{\circ} \mathrm{C}$ departed from normality $(W=0.02)$ ranging between 1.02 and $3.3 \mathrm{~cm}^{2}$ (Fig. 1C). Growth of the same isolates at $15^{\circ} \mathrm{C}$ also departed from normality $(W>0.001)$ and had a positive skewness with colony area ranging between 0.9 and $4.9 \mathrm{~cm}^{2}$ (Fig. 1D). Comparison between the two origins show that at $25^{\circ} \mathrm{C}$ the colonies area of isolates originated from domesticated chickpea was significantly larger $(P<0.001)$ than those originated from C. judaicum. At $15^{\circ} \mathrm{C}$, colonies area of isolates originated from

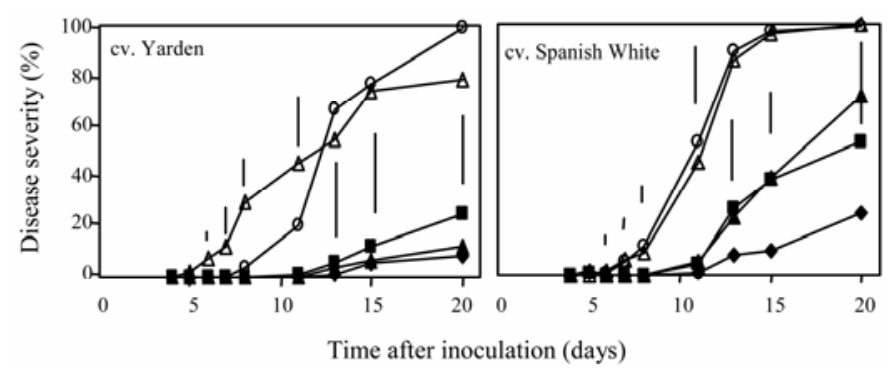

Fig. 2. Disease progress curves of three Didymella rabiei isolates from Cicer judaicum and two isolates from $C$. arietinum on the moderately resistant cv. Yarden and the highly susceptible cv. Spanish White. Isolate from $C$. judaicum: $\mathbf{\square}, \mathrm{M} 305 ; \boldsymbol{\Delta}, \mathrm{Y} 105 ;$ and $\bullet, \mathrm{S} 306$. Isolate from $C$. arietinum: $\triangle, \mathrm{B} 05$ and $\mathrm{O}$, N04. Each point represents the average of 4 replicates. Vertical lines represent the least significant differences at $P=0.05$ as determined by the honestly significant difference (HSD) test. domesticated chickpea were significantly smaller $(P<0.001)$ than those originated from $C$. judaicum.

Aggressiveness of $D$. rabiei isolates on chickpea cultivars. Necrotic lesions, typical to D. rabiei infection, appeared on the stems and petioles of both chickpea cultivars. Disease symptoms of plants inoculated with isolates originated from the domesticated crop appeared 4 to 7 days after inoculation. The disease progressed rapidly and in less than 20 days disease severity reached 80 to $100 \%$ on both cultivars. In plants inoculated with isolates originating from $C$. judaicum, first symptoms were observed 6 to 12 days after inoculation, and by the end of the experiment disease severity ranged from 20 to $70 \%$ on cv. Spanish White and from 5 to $20 \%$ on cv. Yarden (Fig. 2). No morphological differences were observed between symptoms caused by isolates from the two origins.

The linear ANOVA models used to compare the aggressiveness measures of $D$. rabiei isolates originated from domesticated chickpea or from $C$. judaicum are presented in Table 2 and the correlation between the measures are presented in Table 3. All ANOVA models were highly significant and explained more than $81 \%$ of the observed variation of the studied measures. The main factor chickpea cultivar had significant effect only on the AUDPC, while the main factor isolate origin had significant effects on four out of the five aggressiveness measures, namely, incubation period, $\mathrm{T}_{10}$, final disease severity and AUDPC. Interaction effects between these two main factors were insignificant on any of the studied aggressiveness measures, nor were differences between the individual isolates nested within isolate origin. However, a significant interaction effect was observed between chickpea cultivar (main factor) and the individual isolates nested within isolate origin $(\mathrm{CV} \times D$. rabiei $[\mathrm{I}])$ on all the studied measures (Table 2). Further analysis of this interaction is detailed in Table 4. In general, the isolates from domesticated chickpea were more aggressive than those originated from $C$. judaicum as expressed

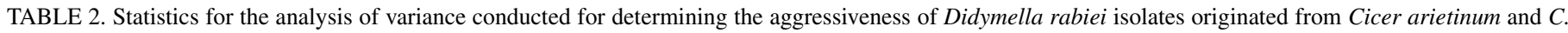
judaicum on two chickpea cultivars ${ }^{\mathrm{v}}$

\begin{tabular}{|c|c|c|c|c|c|}
\hline Source & Incubation period (days) & $\mathrm{T}_{10}$ (days) & Apparent infection rate & Final severity ${ }^{\mathrm{w}}(\%)$ & $\operatorname{AUDPC}^{\mathrm{x}}(\% \times$ days $)$ \\
\hline \multicolumn{6}{|l|}{ ANOVA } \\
\hline Model & $<0.001$ & $<0.0001$ & $<0.0001$ & $<0.0001$ & $<0.0001$ \\
\hline$R^{2}$ & 0.894 & 0.851 & 0.814 & 0.890 & 0.952 \\
\hline \multicolumn{6}{|l|}{$P$ values } \\
\hline Chickpea cultivar (Cv) & 0.077 & 0.206 & 0.159 & 0.100 & $0.027(11.7)^{\mathrm{y}}$ \\
\hline Isolate origin (I) & $0.017(74.1)$ & $0.003(76.2)$ & 0.061 & $0.004(79.0)$ & $0.002(83.2)$ \\
\hline $\mathrm{Cv} \times \mathrm{I}$ & 0.237 & 0.134 & 0.643 & 0.550 & 0.680 \\
\hline D. rabiei $[\mathrm{I}]^{\mathrm{z}}$ & 0.273 & 0.685 & 0.375 & 0.620 & 0.460 \\
\hline $\mathrm{Cv} \times$ D. rabiei $[\mathrm{I}]$ & $0.0152(5.8)$ & $0.019(8.0)$ & $0.005(16.1)$ & $0.005(8.5)$ & $0.001(2.7)$ \\
\hline
\end{tabular}

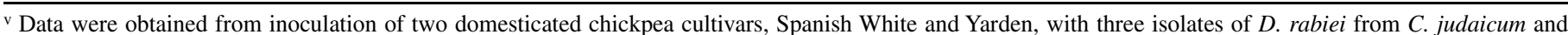
two isolates of $D$. rabiei from $C$. arietinum.

${ }^{w}$ Disease severity values were normalized by an arcsine square root transformation before analysis.

${ }^{x}$ Area under the disease progress curve.

y Variance components (in \%) of the significant effects are indicated in parentheses.

${ }^{\mathrm{z}}$ D. rabiei isolate within isolate origin (D. rabiei $\left.[\mathrm{I}]\right)$ was analyzed as random effect.

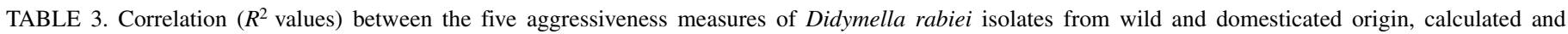
presented separately for Cicer arietinum cultivars and $C$. judaicum accessions

\begin{tabular}{|c|c|c|c|c|c|}
\hline Host & Aggressiveness measures & Incubation period (days) & $\mathrm{T}_{10}$ (days) & Apparent infection rate & Final disease severity (\%) \\
\hline C. arietinum & $\begin{array}{l}\mathrm{T}_{10} \text { (days) } \\
\text { Apparent infection rate } \\
\text { Final disease severity }(\%) \\
\text { AUDPC }^{\mathrm{z}}(\% \times \text { days })\end{array}$ & $\begin{array}{l}0.77 y \\
0.75 \\
0.83 \\
0.83\end{array}$ & $\begin{array}{l}0.71 \\
0.88 \\
0.84\end{array}$ & $\begin{array}{l}0.78 \\
0.82\end{array}$ & 0.89 \\
\hline C. judaicum & $\begin{array}{l}\mathrm{T}_{10} \text { (days) } \\
\text { Apparent infection rate } \\
\text { Final disease severity }(\%) \\
\text { AUDPC }(\% \times \text { days })\end{array}$ & $\begin{array}{l}0.48 \\
0.16 \\
0.31 \\
0.36\end{array}$ & $\begin{array}{l}0.25 \\
0.73 \\
0.78\end{array}$ & $\begin{array}{l}0.55 \\
0.49\end{array}$ & 0.90 \\
\hline
\end{tabular}

y All values were significant at $P \leq 0.05$.

$\mathrm{z}$ Area under the disease progress curve. 
by the shorter incubation period and $\mathrm{T}_{10}$ and the higher AUDPC values on both cultivars (Table 4). Noticeable variation in aggressiveness was observed between the isolates originated from C. judaicum when examined on cv. Spanish White. For example, isolate M305 had relatively high apparent infection rate which did not differ significantly from the domesticated isolate B05, and relatively high final disease severity, which also did not differ significantly from the isolates originated from domesticated chickpea. On the other hand, isolate S306 had a significantly longer incubation period, lower apparent infection rate, and lower
AUDPC than the rest of the isolates originated from $C$. judaicum (Table 4).

Aggressiveness of $\boldsymbol{D}$. rabiei isolates on $\boldsymbol{C}$. judaicum. Typical Ascochyta blight symptoms developed on petioles and stems of all tested C. judaicum accessions. Twenty days after inoculation, the disease severity ranged from low $(<10 \%)$ to very high $(>80 \%)$ (Fig. 3). In general, isolates Y105 and M305 caused higher disease severity than the rest of the isolates, nevertheless, wide variation in the disease progress was observed on different $C$. judaicum accessions (Fig. 3).

TABLE 4. Aggressiveness measures of five Didymella rabiei isolates originated from Cicer arietinum and C. judaicum as determined on two chickpea cultivars

\begin{tabular}{|c|c|c|c|c|c|c|c|}
\hline Cultivar & Isolates origin & D. rabiei isolate & $\begin{array}{l}\text { Incubation period } \\
\text { (days) }\end{array}$ & $\mathrm{T}_{10}$ (days) & $\begin{array}{c}\text { Apparent } \\
\text { infection rate }\end{array}$ & $\begin{array}{c}\text { Final disease } \\
\text { severity }(\%)\end{array}$ & $\begin{array}{l}\text { AUDPCy } \\
(\% \times \text { days })\end{array}$ \\
\hline Spanish White & $\begin{array}{l}\text { C. judaicum } \\
\text { C. arietinum }\end{array}$ & $\begin{array}{l}\text { S306 } \\
\text { Y105 } \\
\text { M305 } \\
\text { N04 } \\
\text { B05 }\end{array}$ & $\begin{array}{c}11.5 \mathrm{a}^{\mathrm{z}} \\
8.0 \mathrm{~b} \\
7.3 \mathrm{~b} \\
5.0 \mathrm{c} \\
4.3 \mathrm{c}\end{array}$ & $\begin{array}{r}15.8 \mathrm{a} \\
13.0 \mathrm{a} \\
13.8 \mathrm{a} \\
8.4 \mathrm{~b} \\
8.7 \mathrm{~b}\end{array}$ & $\begin{array}{l}0.25 \mathrm{~d} \\
0.52 \mathrm{c} \\
0.56 \mathrm{bc} \\
0.78 \mathrm{a} \\
0.75 \mathrm{ab}\end{array}$ & $\begin{array}{l}25.0 \mathrm{c} \\
52.5 \mathrm{bc} \\
71.3 \mathrm{ab} \\
98.5 \mathrm{a} \\
99.5 \mathrm{a}\end{array}$ & $\begin{array}{l}116 \mathrm{c} \\
375 \mathrm{~b} \\
327 \mathrm{~b} \\
922 \mathrm{a} \\
890 \mathrm{a}\end{array}$ \\
\hline Yarden & $\begin{array}{l}\text { C. judaicum } \\
\text { C. arietinum }\end{array}$ & $\begin{array}{l}\text { S306 } \\
\text { Y105 } \\
\text { M305 } \\
\text { N04 } \\
\text { B05 }\end{array}$ & $\begin{array}{r}12.5 \mathrm{a} \\
11.5 \mathrm{a} \\
12.0 \mathrm{a} \\
6.5 \mathrm{~b} \\
4.5 \mathrm{~b}\end{array}$ & $\begin{array}{r}18.5 \mathrm{a} \\
20.7 \mathrm{a} \\
17.8 \mathrm{a} \\
10.2 \mathrm{~b} \\
7.9 \mathrm{~b}\end{array}$ & $\begin{array}{l}0.32 \mathrm{~b} \\
0.36 \mathrm{~b} \\
0.36 \mathrm{~b} \\
0.74 \mathrm{a} \\
0.44 \mathrm{~b}\end{array}$ & $\begin{array}{r}7.5 \mathrm{~b} \\
12.5 \mathrm{~b} \\
23.8 \mathrm{~b} \\
78.5 \mathrm{a} \\
98.5 \mathrm{a}\end{array}$ & $\begin{array}{r}61 \mathrm{~b} \\
39 \mathrm{~b} \\
106 \mathrm{~b} \\
719 \mathrm{a} \\
584 \mathrm{a}\end{array}$ \\
\hline
\end{tabular}

y Area under the disease progress curve.

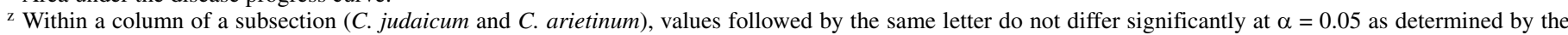
honestly significant difference test.
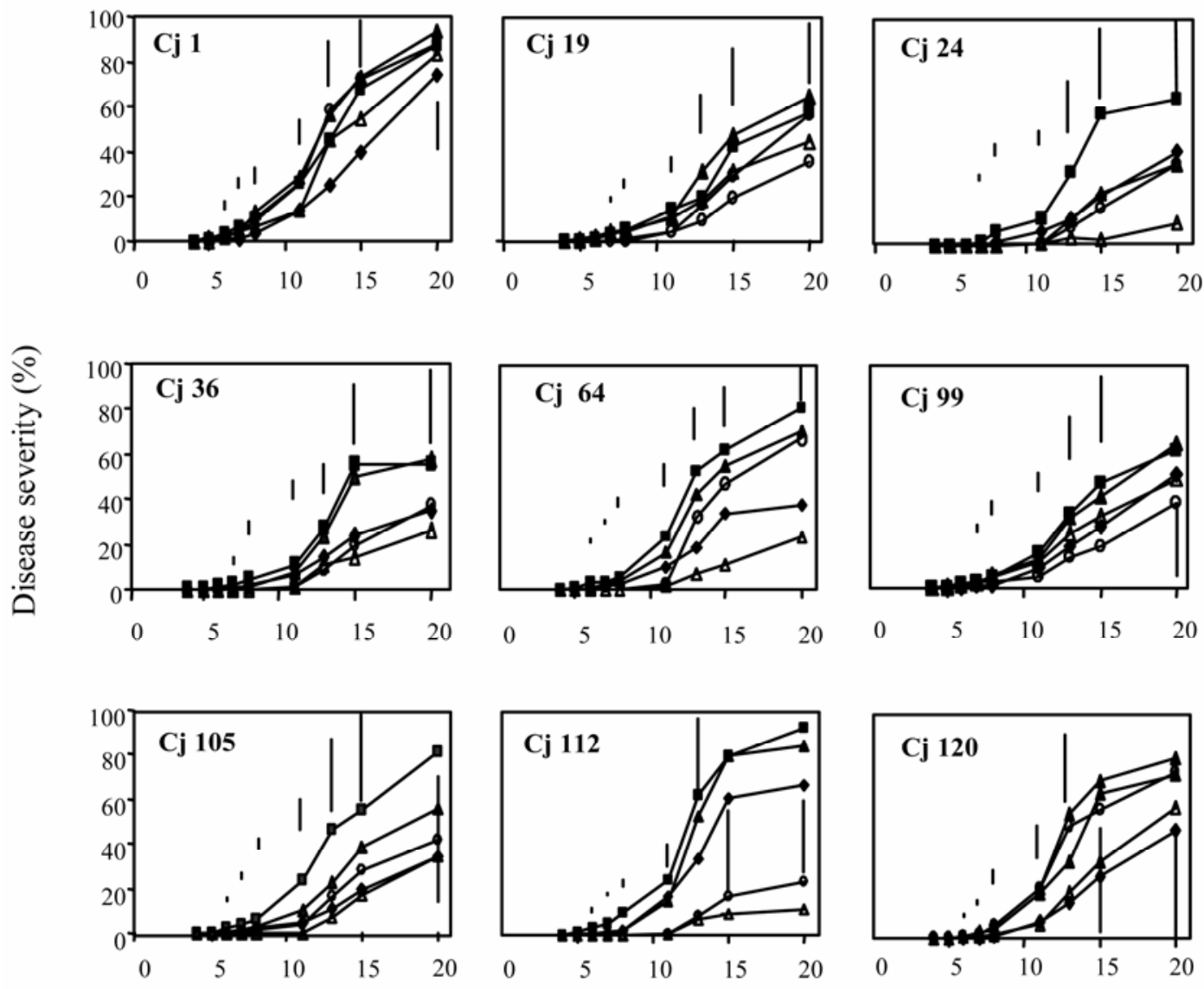

Time after inoculation (Days)

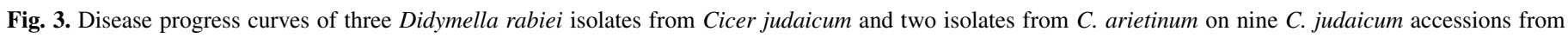

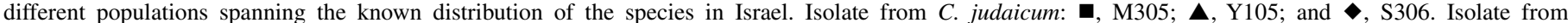

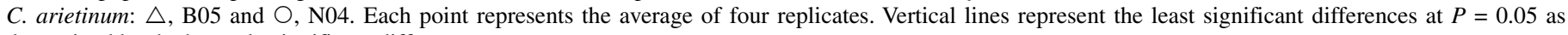
determined by the honestly significant difference test. 
The linear ANOVA models used to compare the aggressiveness measures of the isolates on C. judaicum are presented in Table 5 and the correlation between the measures are presented in Table 3. All models were highly significant and explained 64 to $72 \%$ of the observed variation (except for the apparent infection rate, 23.5\%). The main factor Cicer accession had highly significant effect on all aggressiveness measures. The main factor isolate origin had a significant effect only on the incubation period and final disease severity. The interaction between Cicer accession and isolate origin had highly significant effect on all aggressiveness measures and so was the effect of $D$. rabiei isolates within isolate origin. The interaction Cicer accession $\times$ isolate within isolate origin $(\mathrm{Cj} \times$ D. rabiei $[\mathrm{I}])$ was insignificant (Table 5).

The interaction effects between Cicer accessions $\times$ isolate origin on the incubation period and the D. rabiei isolate within isolate origin on the other four aggressiveness measures are presented in Table 6. Incubation period of isolates from wild origin was significantly shorter than the incubation period of isolates from domesticated origin in six out of the nine tested accessions (Table 6). Significant differences were also found within the two isolate origins. For example, isolate S306 was less aggressive as compared with the other two isolates originated from $C$. judaicum in seven out of the nine $C$. judaicum accessions, in at least one aggressiveness measure. This significantly lower aggressiveness was most apparent in the measures $\mathrm{T}_{10}$ (seven out of nine C. judaicum accessions) and AUDPC (six out of nine C. judaicum accessions) among other cases (Table 6). The low aggressiveness phenotype S306 was not expressed when tested on accessions Cj99 and Cj24 (Table 6). Significant differences between isolates from domesticated chickpea were detected only on two $C$. judaicum accessions. On Cj24 isolate, N04 was significantly more aggressive than B05 in all aggressiveness measures (higher apparent infection rate, lower $\mathrm{T}_{10}$, higher final disease rate, and higher AUDPC). On Cj64, N04 was significantly more aggressive as determined by lower $\mathrm{T}_{10}$, higher final disease rate, and higher AUDPC (Table 6).

\section{DISCUSSION}

Wild relatives of domesticated crops have attracted attention for more than a century now due to their potential for crops improvement (1). Indeed, large volume of data was accumulated on plant diseases of crops wild relatives but mostly on the hosts' resistance $(9,25,34)$. Strong emphasis was put on pathogens infecting wild cereals such as rusts in oats (21), powdery mildew in wild barley $(10,11)$, and Stagonospora in wheat $(18)$, while data concerning pathogens causing diseases in wild legumes and their relationship with the domesticated crops is meager. Among the important legume disease agents are the Ascochyta pathogens that infect a number of legume crops worldwide, causing different degrees of yield losses $(4,26,34)$. Therefore, it is important to improve our understanding of the respective pathosystems involved in these diseases (2). Apart from its agronomic importance, the A. rabiei Cicer pathosystem presents an interesting evolutionary test case. Under domestication, chickpea (C. arietinum) evolved a life cycle different from the rest of the Near Eastern crops and their wild relatives. Near eastern crops kept their autumn-germination summer-maturation cycle while chickpea became a spring-sown crop. This shift in the crop life cycle was apparently driven by the extreme vulnerability of chickpea to Ascochyta blight during the rainy season (3). Due to this shift, a gap of up to four months was formed between the growth season of Levantine wild Cicer species and domesticated chickpea. It is true though that in late March and early April the cultigen and its wild relatives grow sympatrically, but these months are relatively warm and dry in the Levant and Ascochyta distribution through rain splashes is quite limited $(3,4,28,32)$. In the last 50 years, along with modern agricultural practice, winter chickpea cropping became a routine in Israel $(28,29)$, resulting in greater temporal and spatial overlap between the growth of $C$. judaicum and chickpea. Few major differences in the pathogen ecology and aggressiveness may be expected following millennia of habitat segregation. Two such differences were investigated in this research. First, isolates from domesticated origin may be adapted to survive and develop at higher temperatures than isolates that develop in the winter on wild $C$. judaicum. Second, Ascochyta mostly spread during rain events and mild temperatures. Hence, it is reasonable to assume that lower frequency of rain events (under spring cropping) will serve as a selection pressure on $D$. rabiei that grow in the spring season to establish themselves faster in the plant tissues and to colonize larger leaf area in the short time window of favorable conditions.

As expected, significant differences were detected between isolates from the different host origins. Isolates from domesticated chickpea grew faster at high temperature implying that they are better adapted to the hotter late spring conditions. Indeed the positive skewness of the frequency distribution may represent a directional selection among the source population toward better adaptation to higher temperatures (Fig. 1A and B). At low temperature, the same isolates had significantly smaller colony area reflecting weaker adaptation to colder conditions which are less common in the late spring. Growth of the isolates from $C$. judaicum was nearly similar at both temperatures although the positive skewness of the distribution (Fig. 1C and D) hints for better adaptation at lower temperature. It is important to corroborate these in vitro obtained data with whole plant experiments.

Major differences in aggressiveness were detected between isolates from the different origins. The correlations between the five aggressiveness measures were all significant (Table 3 ). Interestingly the $R^{2}$ values obtained for isolates of domesticated origin

TABLE 5. Statistics for the analysis of variance conducted for determining the aggressiveness of Didymella rabiei isolates originated from Cicer arietinum and $C$. judaicum on nine $C$. judaicum accessions ${ }^{\mathrm{v}}$

\begin{tabular}{|c|c|c|c|c|c|}
\hline Source & Incubation period (days) & $\mathrm{T}_{10}$ (days) & Apparent infection rate & Final severity $(\%)^{\mathrm{w}}$ & $\operatorname{AUDPC}(\% \times \text { days })^{\mathrm{x}}$ \\
\hline \multicolumn{6}{|l|}{ ANOVA } \\
\hline Model & $<0.001$ & $<0.001$ & $<0.001$ & $<0.001$ & $<0.001$ \\
\hline$R^{2}$ & 0.721 & 0.688 & 0.235 & 0.641 & 0.667 \\
\hline Cicer accessions $(\mathrm{Cj})$ & $<0.001(9.7)^{\mathrm{y}}$ & $<0.001(11.9)$ & $<0.001(9.5)$ & $<0.001(15.5)$ & $<0.001(15.1)$ \\
\hline Isolate origin (I) & $0.002(46.8)$ & 0.163 & 0.210 & 0.380 & 0.226 \\
\hline $\mathrm{Cj} \times \mathrm{I}$ & $0.001(22.0)$ & $<0.001$ (20.9) & $0.006(12.3)$ & $<0.001(19.8)$ & $<0.001(17.8)$ \\
\hline
\end{tabular}

${ }^{v}$ Data obtained from inoculation of nine C. judaicum accessions with three isolates of D. rabiei from C. judaicum and two isolates of D. rabiei from C. arietinum.

${ }^{\mathrm{w}}$ Disease severity values normalized by an arcsine square root transformation before analysis.

${ }^{x}$ Area under the disease progress curve.

y Variance components of the significant effects are indicated in parentheses.

${ }^{\mathrm{z}}$ D. rabiei isolate within isolate origin (D. rabiei $\left.[\mathrm{I}]\right)$ was analyzed as random effect. 
are higher compared with those obtained for isolates of wild origin (Table 3). At present we have no information on the genetic control of those aggressiveness phenotypes (in the pathogen) nor on the genetic base of the hosts response. Therefore any further discussion of these correlation matrixes is premature.

The isolates from domesticated origin were more aggressive upon domesticated chickpea (their original host) compared with isolates originated from wild $C$. judaicum in all the examined aggressiveness measures (Table 4). The main factor isolate origin explained 74 to $83 \%$ of the models' total variance (Table 2). These results indicate that isolate origin (domesticated chickpea versus $C$. judaicum) is the most decisive factor affecting $D$. rabiei aggressiveness on chickpea cultivars. Although isolates from $C$. judaicum have the potential to infect commercial chickpea fields, it is most likely that the more aggressive isolates from domesticated origin would cause greater part of the damage in chickpea crops. Still, significant interaction was observed between the known response of the cultivar and the isolates, within origin. For example, in the highly susceptible cv. Spanish White, significant differences were detected between the isolates from $C$. judaicum themselves. Moreover, in some cases differences in aggressiveness between isolates originated from $C$. judaicum and domesticated chickpea were insignificant (Table 4). A similar phenomenon was reported by Krupinsky (18) while working on Stagonospora of domesticated wheat and wild perennial grasses. In his work, isolates originated from wild species were less aggressive than isolates from domesticated origin, but with a wider variance in aggressiveness, including a few highly aggressive isolates from wild origin.

Challenging C. judaicum accessions with isolates from both origins showed that isolates originated from $C$. judaicum were usually more aggressive than isolates from domesticated chickpea. This general higher aggressiveness on $C$. judaicum rules out the hypothesis that isolates from $C$. arietinum are generally more

TABLE 6. Aggressiveness measures of five Didymella rabiei isolates from wild and domesticated origin as determined on nine Cicer judaicum accessions

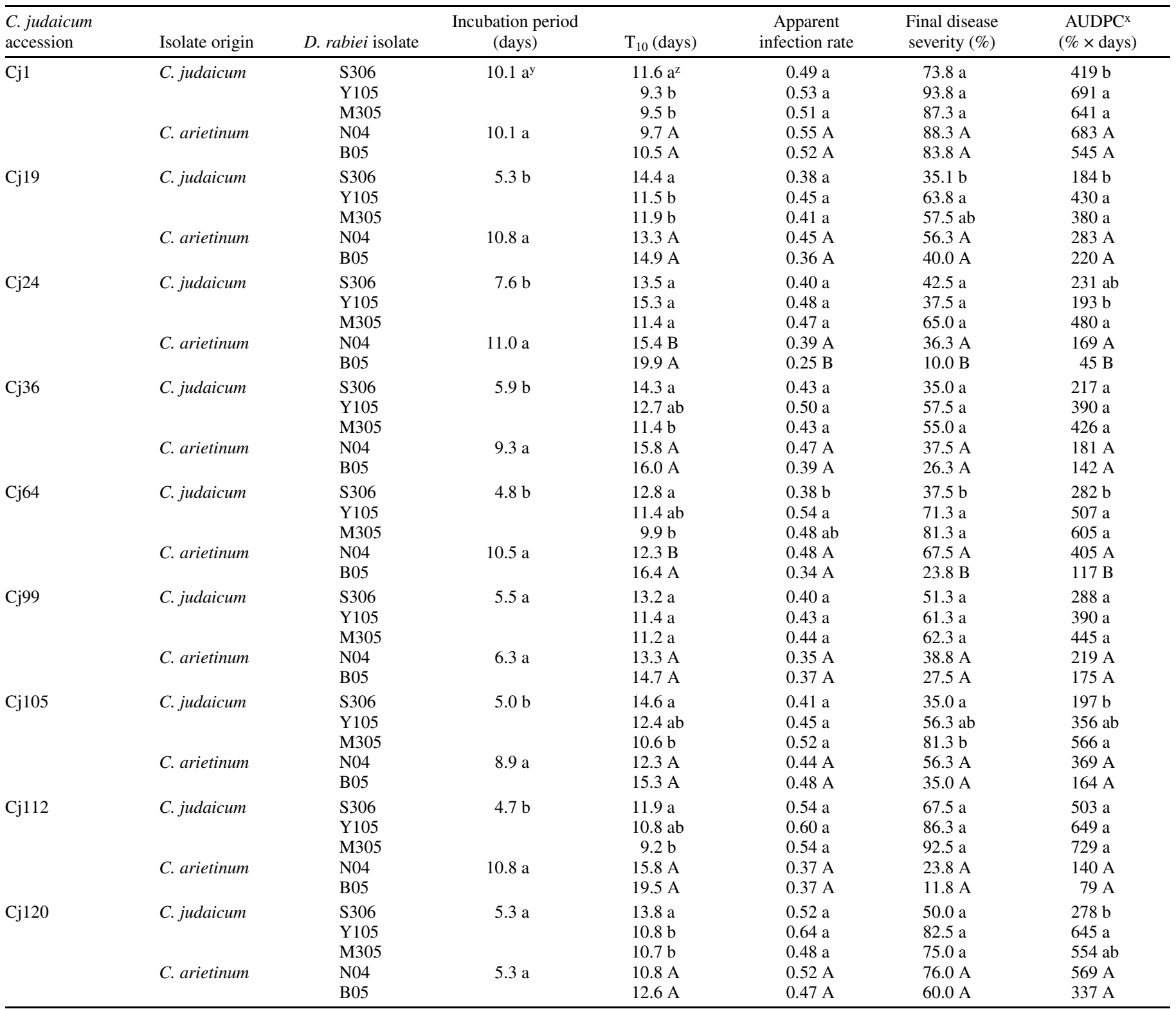

\footnotetext{
${ }^{x}$ Area under the disease progress curve.

$y$ Values in this column represent the average incubation period for the respective origin of the isolates. Values followed by the same letter within the incubation period column for each $C$. judaicum accession do not differ significantly at $\alpha=0.05$.

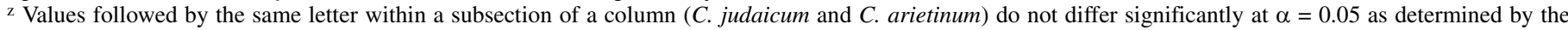
honestly significant difference test. Small letters represent differences within isolate from wild origin; capital letters represent differences within isolates from domesticated origin.
} 
aggressive than isolates from $C$. judaicum. On the other hand, it may raise a new hypothesis concerning some kind of host specialization between $D$. rabiei and its two hosts. Unfortunately the small numbers of isolates used in these experiments are not sufficient to test this hypothesis but it may serve as a reasonable working hypothesis for future research. Significant differences were also found between isolates originated from $C$. judaicum, with isolate S306 expressing significantly lower aggressiveness measures than the rest of the isolates on most accessions (Tables 5 and 6). Wide variance between isolates originated from wild origin was reported by Dinoor and Eshed (10) while testing Blumeria graminis isolates on wild barley and by Thrall et al. (33) in the Alternaria brassicicola/Cakile maritime pathosystem. Such variation is expected due to greater niche heterogeneity in the wild compared with agroecosystems. One of the two cases in which isolate S306 was as aggressive as the rest of the isolates originated from $C$. judaicum occurred while challenging accession Cj24 (Table 6). This $C$. judaicum accession was collected from E'ziona, situated in proximity $(1 \mathrm{~km})$ to the collection point of isolate S306. In addition, isolate N04 was collected in the nearby chickpea field (about $50 \mathrm{~m}$ away from Eziona). Indeed, $C$. judaicum $\mathrm{Cj} 24$ was the only accession on which isolate N04 (from domesticated chickpea) showed higher aggressiveness than isolate B05 (of domesticated origin). These observations may be accounted for by prevalence of local adaptations among the different pathogen populations $(30,33)$, in addition to other genetic and environmental factors affecting pathogen aggressiveness $(17,30)$.

Few Cicer accessions such as $\mathrm{Cj} 1$ and $\mathrm{Cj} 120$ were almost equally susceptible to isolates from wild and domesticated origin (Table 6). Therefore, occasional cases in which susceptible $C$. judaicum serve as hosts to isolates from domesticated origin cannot be totally ruled out. To test this hypothesis, epidemiological and molecular tools should be integrated, similar to the work in other systems in which molecular markers were used to track source of inoculum $(24,27)$ and pathogen evolutionary origin (31).

This work implies that the sympatric chickpea/wild Cicer systems sustain two different phenotypes of D. rabiei which differ in their ecological affinities and aggressiveness. This finding is interesting from an evolutionary perspective, as there is a fair chance that certain D. rabiei isolates were diverged somewhere along the evolutionary history of $C$. arietinum during the last 10,000 years. In this case, these differences between the different pathogen phenotypes might have been provoked unintentionally by selection in man-made agroecosystems. Summer cropping with higher seasonal temperatures and lower incidence of rain events presents an ecological challenge before the pathogen, which in its wild origin develops mostly during the Levantine winter. Several millennia of summer chickpea cropping may have provided a certain degree of isolation required to trigger populations' divergence processes (23). Under such an assumption, different ecological requirements and maybe partial host specialization are expected to develop in parallel, reflecting the different environmental conditions prevailing in the two systems (wildwinter growth versus domesticated-spring growth).

The apparent co-existence of these two different $D$. rabiei phenotypes may provide the opportunity to identify which characters were altered during this evolutionary process and especially those that govern the pathogen aggressiveness. For example, the incubation period was the most common aggressiveness measure in which isolates from $C$. judaicum and from domesticated chickpea differed from each other (Table 5). This may imply that differences in aggressiveness between isolates from the two sources are caused primarily by the higher ability of $D$. rabiei isolates from each origin to penetrate and establish on their original host. From an ecological perspective, it should be borne in mind that under extreme environmental conditions germination and penetra- tion are the most vulnerable phase in the pathogen life cycle (32). The aggressiveness study of progenies from a cross between D. rabiei isolates originated from the two hosts is currently under way in collaboration with T. L. Peever (Pullman, WA) and may be used to answer these issues. This study may also provide insight into the genetic basis of the ecological adaptation of the pathogen, its aggressiveness components, and the possible genetic correlations between the different determinants of pathogenic fitness in this important pathosystem.

\section{ACKNOWLEDGMENTS}

We thank H. Vintal for skillful laboratory assistance, and S. Morin and $\mathrm{R}$. Ben-David for their help in biometric analyses. O. Frenkel is a recipient of the Whole Organism Stipend, initiated by ARO and the Hebrew University of Jerusalem.

\section{LITERATURE CITED}

1. Aaronsohn, A. 1910. Agricultural and Botanical Explorations in Palestine. Bull. 180. U.S. Dep. Agric., Washington DC.

2. Abbo, S., Frenkel, O., Sherman, A., and Shtienberg, D. 2007. The sympatric Ascochyta pathosystems of near eastern legumes, a key for better understanding of pathogen biology. Eur. J. Plant Pathol. 119:111-118.

3. Abbo, S., Shtienberg, D., Lichtenzveig, J., Lev-Yadun, S., and Gopher, A. 2003. The chickpea, summer cropping, and a new model for pulse domestication in the ancient near east. Q. Rev. Biol. 78:435-448.

4. Akem, C. 1999. Ascochyta blight of chickpea: Present status and future priorities. Int. J. Plant Manage. 45:131-137.

5. Barve, M. P., Arie, T., Salimath, S. S., Muehlbauer, F. J., and Peever, T. L. 2003. Cloning and characterization of the mating type (MAT) locus from Ascochyta rabiei (teleomorph: Didymella rabiei) and a MAT phylogeny of legume-associated Ascochyta spp. Fungal Genet. Biol. 39:151-167.

6. Ben-David, R., Lev-Yadun, S., Canan, C., and Abbo, S. 2006. Ecogeography and demography of Cicer judaicum Boiss., a wild annual relative of domesticated chickpea. Crop Sci. 46:1360-1370.

7. Burdon, J. J., Thrall, P. H., and Ericson, L. 2006. The current and future dynamics of disease in plant communities. Annu. Rev. Phytopathol. 44:19-39.

8. Dinoor, A. 1974. Role of wild and cultivated plants in the epidemiology of plant diseases in Israel. Annu. Rev. Phytopathol. 12:413-436.

9. Dinoor, A., and Eshed, N. 1984. The role and importance of pathogens in natural plant communities. Annu. Rev. Phytopathol. 22:443-466.

10. Dinoor, A., and Eshed, N. 1987. The analysis of host and pathogen populations in natural ecosystems. Pages 75-88 in: Populations of Plant Pathogens: Their Dynamics and Genetics. M. S. Wolfe, and C. E. Caten, eds. Blackwell Scientific Publications, Oxford, UK.

11. Eshed, N., and Wahl, I. 1975. Role of wild grasses in epidemics of powdery mildew on small grains in Israel. Phytopathology 65:57-63.

12. Frenkel, O., Shtienberg, D., Abbo, S., and Sherman, A. 2007. The sympatric Ascochyta complex of wild Cicer judaicum and domesticated chickpea. Plant Pathol. 56:464-471.

13. Geistlinger, J., Weising, K., Winter, P., and Kahl, G. 2000. Locus-specific microsatellite markers for the fungal chickpea pathogen Didymella rabiei (anamorph) Ascochyta rabiei. Mol. Ecol. 9:1939-1941.

14. Harikrishnan, R., and Yang, X. B. 2004. Recovery of anastomosis groups of Rhizoctonia solani from different latitudinal positions and influence of temperatures on their growth and survival. Plant Dis. 88:817-823.

15. Harlan, J. R. 1976. Disease as a factor in plant evolution. Annu. Rev. Phytopathol. 14:35-51.

16. Kaiser, W. J., and Kusmenoglu, I. 1997. Distribution of mating type and the teleomorph of Ascochyta rabiei on chickpea in Turkey. Plant Dis. $81: 1284-1287$

17. Kaltz, O., and Shykoff, J. A. 1998. Local adaptation in host-parasite systems. Heredity 81:361-370.

18. Krupinsky, J. M. 1997. Aggressiveness of Stagonospora nodorum isolates from perennial grasses on wheat. Plant Dis. 81:1032-1036.

19. Ladizinsky, G., and Adler, A. 1976. Genetic relationships among the annual species of Cicer L. Theor. Appl. Genet. 48:197-203.

20. Leppik, E. E. 1970. Gene centers of plants as sources of disease resistance. Annu. Rev. Phytopathol. 8:323-344.

21. Leonard, K. J., Anikster, Y., and Manisterski, J. 2004. Patterns of virulence in natural populations of Puccinia coronata on wild oat in Israel and in agricultural populations on cultivated oat in the United States. Phytopathology 94:505-514.

22. Lev-Yadun, S., Gopher, A., and Abbo, S. 2000. The cradle of agriculture. Science 288:1602-1603. 
23. Mayr, E. 1970. Populations, Species, and Evolution. Belknap, Harvard University Press Cambridge, MA.

24. Milgroom, M. G., and Peever, T. L. 2003. Population biology of plant pathogens: The synthesis of plant disease epidemiology and population genetics. Plant Dis. 87:608-617.

25. Muehlbauer, F. J., Kaiser, W. J., and Simon, C. J. 1994. Potential for wild species in cool season food legume breeding. Euphytica 73:109-114.

26. Nene, Y. L., and Reddy, M. V. 1987. Chickpea diseases and their control. Pages 233-370 in: The Chickpea. M. C. Saxena and K. B. Singh, eds. CAB International, Wallingford, UK.

27. Peever, T. L., Salimath, S. S., Su, G., Kaiser, W. J., and Muehlbauer, F. J. 2004. Historical and contemporary multilocus population structure of Ascochyta rabiei (teleomorph: Didymella rabiei) in the Pacific Northwest of the United States. Mol. Ecol. 13:291-309.

28. Shtienberg, D., Gamliel-Atinsky, E., Retig, B., Brener, S., and Dinoor, A. 2005. Significance of preventing primary infections by Didymella rabiei and development of a model to estimate the maturity of pseudothecia. Plant Dis. 89:1027-1034.

29. Shtienberg, D., Vintal, H., Brener, S., and Retig, B. 2000. Rational management of Didymella rabiei in chickpea by integration of genotype resistance and curative application of fungicides. Phytopathology 90:834842.

30. Sicard, D., Pennings, P. S., Grandcl'ement, C., Acosta, J., Kaltz, O., and
Shykoff, J. A. 2007. Specialization and local adaptation of a fungal parasite on two host plant species as revealed by two fitness traits. Evolution 61:27-41.

31. Stukenbrock, E. H., Banke, S., Javan-Nikkhah, M., and McDonald, A. 2007. Origin and domestication of the fungal wheat pathogen Mycosphaerella graminicola via sympatric speciation. Mol. Biol. Evol. 24:398-411.

32. Trapero-Casas, A., and Kaiser, W. J. 1992. Influence of temperature, wetness period, plant age and inoculum concentration on infection and development of Ascochyta blight of chickpea. Phytopathology 82:589596.

33. Thrall, P. H., Barrett, L. G., Burdon, J. J., and Alexander, H. M. 2005. Variation in pathogen aggressiveness within a metapopulation of the Cakile maritime-Alternaria brassicicola host-pathogen association. Plant Pathol. 54:265-274.

34. Tivoli, B., Baranger, A., Avila, C. M., Banniza, S., Barbetti, M., Chen, W., Davidson, J., Lindeck, K., Kharrat, M., Rubiales, D., Sadiki, M., Sillero, J. C., Sweetingham, M., and Muehlbauer, F. J. 2006. Screening techniques and source of resistance to foliar diseases caused by major necrotrophic fungi in grain legumes. Euphytica 147:223-253.

35. van der Maesen, L. J. G. 1972. Cicer L., A monograph of the genus, with special reference to the chickpea (Cicer arietinum L.). Veenman and Sons, Wageningen, the Netherlands. 